\title{
PENINGKATANAPRESIASI SENI DAN BUDAYA MASYARAKAT DALAM UPAYA MEWUJUDKAN DESA MERGOWATI SEBAGAI DESA WISATA
}

\author{
Soemaryatmi \\ Jurusan Tari \\ Fakultas Seni Pertunjukan ISI Surakarta \\ Email: soemaryatmi@isi-ska.ac.id
}

\begin{abstract}
Abstrak
Peningkatan Apresiasi Seni Dan Budaya Masyarakat Dalam Upaya Mewujudkan Desa Mergowati Sebagai Desa Wisata, merupakan kegiatan dalam rangka meningkatkan kesadaran masyarakat Desa Mergowati terhadap potensi seni budaya yang dimiliki untuk dijadikan industri wisata. Mergowati adalah wilayah pedesaan yang memiliki lingkungan alam yang sejuk asri, dan pemandangan yang indah serta kehidupan sosial masyarakat yang ramah dan penuh kekeluargaan. Desa Mergowati memiliki sejarah yang menarik, didukung dengan situs-situs peninggalan Kerajaan Mataram dan memiliki seni budaya serta kerajinan tangan terbuat dari bambu. Metode apresiasi dengan pendekatan aplikatif dan dengan meminjam pemikiran Alfian tentang kreatif, digunakan untuk membahas bagaimana meningkatkan apresiasi seni tradisional masyarakat Desa Mergowati, dan bagaimana meningkatkan kreativitas pengrajin anyaman bambu. PPM Tematik di Desa Mergowati kali ini difokuskan pada peningkatan apresiasi seni tradisioal, workshop pemanfaatan bambu untuk cinderamata, dan mengapresiasi tradisi budaya (Grebeg Gunung Boto). Hasil kegiatan dapat disampaikan sebagai berikut, (1) Pelatihan seni tradisional Tari Kuda Lumping, Tari Kreasi Baru: Tari Rigen, Tari Kupu-Kupu, Tari Merak, Tembang Mocopat, Tembang Dolanan. (2) Workshop pemanfaatan bambu: Lampu Hias, Pot Gerabah Hias, Gantungan Kunci. Diharapkan muncul kegiatan yang bernuansa ekonomi kreatif.
\end{abstract}

Kata kunci: Apresiasi, Seni, Mergowati, Wisata

\begin{abstract}
Increasing the Appreciation of Arts and Culture in the Community Efforts to Realize Mergowati as a Tourism Village, is an activity in order to increase the awareness of the Mergowati people to the potential of the arts and culture they have to make into the tourism industry. Mergowati is a rural area which has a cool natural environment, beautiful scenery and social life that is friendly and full of family. Mergowati village has an interesting history, supported by sites of the kingdom of Mataram and has cultural and handicraft made from bamboo. The appreciation method, with an applicative approach and by borrowing Alfian's thoughts about creative, is used to discuss how to increase the appreciation of traditional art from the people of Mergowati Village, and how to increase the creativity of woven bamboo craftsmen. Thematic PPM in Mergowati Village this time is focused on increasing appreciation of traditional art, workshops on the use of bamboo for souvenirs, and appreciating cultural traditions (Grebeg Gunung Boto). The results of the activities can be delivered as follows, (1) Traditional arts training on Kuda Lumping Dance, New Creative Dance: Rigen Dance, Kupu Kupu Dance, Merak Dance, Mocopat Song, Dolanan Song. (2) Workshop on the use
\end{abstract}


of bamboo: Decorative lamps, decorative pottery pots, key chains. It is hoped that creative economic activities will emerge.

Keywords: Appreciation, Art, Mergowati, Tourism

\section{LATAR BELAKANG}

Desa Mergowati merupakan salah satu dari 14 (empat belas) desa yang termasuk wilayah Kecamatan Kedu. Batas wilayah desa sebelah utara Desa Gondang Wayang, sebelah selatan Desa Mojotengan sebelah timur Desa Karangtejo, sebelah barat Desa Kundisari. Desa Mergowati yang terletak di ketinggian $710 \mathrm{~m}$ dari permukaan laut dan berjarak sekitar 4,5 km dari Ibu Kota Kecamatan Kedu dan 10,5 km dari Ibu Kota Kabupaten Temanggung. Desa Mergowati termasuk desa besar yang berurutan ketiga se- Kecamatan Kedu, Tetapi memiliki jalan yang paling panjang kurang lebih $17 \mathrm{~km}$. Perjalanan dapat ditempuh dengan kendaraan roda empat, maupun kendaraan lain karena jalan desa sudah diaspal. Kondisi jalan naik turun, pemandangan alam sekitar sangat menarik perhatian.

Desa Mergowati memiliki 11 (sebelas) dusun yaitu, Libak, Dukuh, Ngebrak, Mergosari, Sambung, Salam, Letih, Kapal, Ndangun, Ndruju, dan Tugu, yang terdiri dari 12 (dua belas) Rukun warga (RW) dan 37 (tiga puluh tujuh) Rukun Tetangga (RT) dan terdapat 1.453 rumah tangga. Jumlah penduduk 5130 jiwa, terdiri dari 2678 jiwa Laki-laki dan 2614 jiwa Perempuan. Penduduk usia 15 (lima belas) tahun ke atas bermata pencaharian petani tanaman pangan, peternak, petani tanaman kehutanan, industri pengolahan, bangunan, pedagang, pekerja di hotel dan rumah makan, dan ada jasa-jasa lainnya. Ada juga pekerjaan sambilan yaitu membuat anyaman dari bambu, dengan kreativitas masing-masing.

Tanaman pangan yang dikembangkan antara lain padi, jagung, ketela pohon, ketela rambat, kedelai, dan kacang tanah adalah dari tanaman perkebunan yaitu tembakau, kopi, cengkeh, jahe dan kelapa.
Desa Mergowati merupakan wilayah yang cukup strategis untuk dilakukan Pengabdian Pada Masyarakat (PPM) Tematik, mengingat potensi seni dan budaya yang dimiliki masyarakat setempat, dan situs-situs peninggalan Jaman Mataram. Jenis kesenian yang ada di antaranya tarian Islam rebana, Warokan dan Kuda lumping. Kesenian tradisional di Desa Mergowati lahir dengan kesederhanaan dan menjunjung tinggi kearifan lokal serta budaya-budaya yang berkembang di tengah masyarakat. Tradisi budaya setempat yang sampai saat ini secara rutin masih dilakukan oleh masyarakat adalah upacara Nyadran. "Nyadran" sendiri berasal dari bahasa Sansekerta, yaitu "Sraddha" yang artinya keyakinan. Implementasi "Nyadran" sendiri adalah serangkaian upacara yang dilakukan oleh masyarakat Jawa, terutama masyarakat pedesaan dalam membersihkan makam leluhur, tabur bunga, yang diakhiri dengan upacara kenduri selamatan, atau bancakan. Upacara "Nyadran" biasanya dilakukan pada saat menjelang bulan puasa, atau bulan suci Ramadhan. Menurut dalam hitungan kalender Jawa, adalah bulan Ruwah.

Selain kesenian tradisional di Desa Mergowati juga terdapat beberapa situs peninggalan Jaman Mataram. Salah satu di antaranya yaitu sebuah Gumuk atau bukit, namanya Gumuk Boto letaknya sebelah utara Desa Kerokan, Kecamatan Kedu, Kabupaten Temanggung Jawa Tengah. Di tengah Gumuk terdapat situs peninggalan berupa relief dan Gentong yang terbuat dari batu. Konon ceritanya dahulu Gumuk menjadi tempat persembunyian anak buah Pangeran Diponegoro salah satu pahlawan kemerdekaan tetapi sampai sekarang belum ada penelitian yang membuktikan secara ilmiah peninggalan dan saat ini orang menyebutnya Gunung Boto. Selain Gunung Boto beberapa peninggalan lainnya yaitu Watu Gong, Batu Tapak Kuda, Gunung Pawon, dan Makam Batik 


\section{Abdi Seni Jurnal Pengabdian Kepada Masyarakat}

Madrim yang sering dikunjungi oleh orang dari luar Desa Mergowati.

\section{PERMASALAHAN}

Desa Mergowati, Kecamatan Kedu Kabupaten Temanggung kondisi masyarakatnya masih menjunjung tinggi nilai-nilai adat dan kesenian tradisional setempat. Kepala desa dan warga masyarakat sangat mengharapkan Desa Mergowati dapat menjadi desa wisata. Desa wisata didefinisikan sebagai suatu wilayah pedesaan yang memiliki potensi keunikan dan daya tarik wisata yang khas, baik berupa karakter fisik lingkungan alam pedesaan dan kehidupan sosial budaya masyarakat, yang dikelola dikemas secara menarik serta alami dengan pengembangan fasilitas pendukung wisatanya. Desa wisata adalah suatu bentuk integrasi antara atraksi, akomodasi dan fasilitas pendukung yang disajikan dalam suatu struktur kehidupan masyarakat yang menyatu dengan tata cara dan tradisi yang berlaku. Dengan melihat definisi seperti penjelasan tersebut, maka Desa Mergowati mempunyai potensi untuk menjadi desa wisata. Bagaimana mengembangkan, mengemas, mengelola potensi seni budaya yang ada, dan tak kalah penting dukungan sarana, prasarana serta infrastruktur yang memadai.

Harapan Desa Mergowati menjadi desa wisata tidak akan dapat tercapai apabila tidak ada kerjasama dengan pemerintah daerah, dan pihak luar seperti dinas kebudayaan, antropolog, perguruan tinggi dan instansi-instansi terkait. Oleh karenanya perlu upaya dan strategi secara bertahap baik yang disusun dalam program jangka pendek maupun jangka panjang. Dengan latar belakang tersebut maka sasaran Pengabdian Pada Masyarakat (PPM) Tematik adalah bagaimana meningkatkan apresiasi seni tradisioal bagi warga masyarakat Desa Mergowati Kecamatan Kedu? Agar kecintaan dan kebanggan terhadap seni dan budaya yang dimiliki semakin berkembang, serta bagaimana meningkatkan kreativitas masyarakat pengrajin anyaman bambu, tidak hanya memproduksi alat-alat rumah tangga tetapi juga handycraft untuk cinderamata?

\section{METODOLOGI}

\section{a. Solusi yang ditawarkan}

\section{Metode}

Berangkat dari permasalahan mitra maka pendampingan dilakukan dengan metode kaji tindak dan tindakan kreatif inovatif. Sikap kreatif merupakan proses berpikir untuk melahirkan ide yang baru, dan inovasi merupakan proses aplikasi gagasan untuk diwujudkan ke dalam suatu tindakan atau perilaku (Alfian, 1986:154).

Pendampingan menggunakan pendekatan sharing and sugestion yaitu tidak menggurui tetapi saling berbagi pengalaman secara dialogis dengan mengacu pada kerja kreatif dalam kesenian tradisional. Selain dengan pendekatan sharing and sugestion juga menggunakan metode Apresiasi. Apresiasi adalah suatu proses atau bentuk penghargaan dan penilaian terhadap suatu hal. Memberikan apresiasi kepada orang lain atas karyanya akan memberikan dampak bagi individu dan masyarakat. Melalui metode apresiasi dengan pendekatan aplikatif diharapkan masyarakat dapat menghargai kesenian tradisional, sehingga berinisiatif memulai kegiatan kegiatan sosial untuk memperbaiki situasi dan kondisi diri sendiri.

\section{Langkah-langkah}

Untuk pelaksanaan Pengabdian Pada Masyarakat (PPM)Tematik dengan judul Peningkatan Apresiasi Seni dan Budaya Masyarakat Dalam Upaya Mewujudkan Desa Mergowati Sebagai Desa Wisata maka perlu disusun langkahlangkah dalam pelaksanaannya sebagai berikut,

a. Survey/Observasi

Survey atau observasi lapangan dilakukan untuk mengetahui situasi dan kondisi Desa Mergowati Kecamatan Kedu, Kabupaten Temanggung. Observasi dilakukan pada tanggal 17 Juli 2018. Hasil dari pengamatan dan pengumpulan data disusun program kerja yang disebar ke dalam 
bentuk kegiatan-kegiatan antara lain pelatihan kesenian tradisional, workshop, pembuatan mural dan menghias caping dan melestarikan budaya lokal(Grebeg Gunung Boto).

b. Identifikasi Masalah

Bedasarkan dari hasil pengamatan dan pengumpulan data maka dapat diketahui bahwa 1. Kesenian tradisionil yang ada di Desa Mergowati perlu ada penggarapan kembali, 2. Potensi kerajinan tangan yang terbuat dari bambu perlu dioptimalkan melalui sentuhan kerja kreatif.

c. Perancangan Kegiatan

Dari hasil identifikasi masalah dan melalui musyawarah bersama warga dan perangkat desa maka disusun program kerja sebagai solusi pemecahannya. Pemilihan kegiatan tersebut berdasarkan pada skala prioritas. Sebagai sasaran obyek maka yang terlibat dalam kegiatan Pengabdian Pada Masyarakat (PPM) Tematik yaitu, warga masyarakat, anak-anak Sekolah Dasar (SD) dan Sekolah Menengah Pertama (SMP), karang taruna, kelompok kesenian, dan home industry.

\begin{tabular}{|c|l|l|} 
No. & \multicolumn{1}{|c|}{ Program } & \multicolumn{1}{c|}{ Kegiatan/Materi } \\
\hline 1. & Survey & Observasi di Desa Mergowati \\
\hline 2. & $\begin{array}{l}\text { Pelatihan kesenian } \\
\text { tradisional. }\end{array}$ & $\begin{array}{l}\text { 1. Tari Kuda Lumping. } \\
\text { 2. Tari Kreasi Baru (Tari Rigen, Tari Kupu- } \\
\text { Kupu, Tari Merak). } \\
\text { 3. Tembang Mocopat, Tembang Dolanan. }\end{array}$ \\
\hline 3. & Workshop. & $\begin{array}{l}\text { 1. Pemanfaatan bambu sebagai cup lampu, } \\
\text { vandal. } \\
\text { 2. Branding kopi Gunung Boto. } \\
\text { 3. Pembuatan ornamen pada gerabah pot. } \\
\text { 4. Pembuatan gantungan kunci. }\end{array}$ \\
\hline 4. & $\begin{array}{l}\text { Pembuatan Mural } \\
\text { dan Menghias }\end{array}$ & $\begin{array}{l}\text { 1. Pengecetan Mural Balai Desa. } \\
\text { 2. Menghias Caping sejumlah 125 buah untuk } \\
\text { festival Gunung Boto. }\end{array}$ \\
\hline 5. & Pelestarian budaya. & - Perancangan Model Wisata Ritual. \\
\hline
\end{tabular}

d. Pendampingan

Proses pendampingan dilakukan melaui dalam kerja kreatif dalam bentuk-bentuk pelatihan dan workshop. Pelatihan dilakukan pada kelompok kesenian Kridha Turonggo di Dusun Kapal. Workshop pengembangan handycraft, dari bambu dilaksanakan bersama pemuda karang taruna di Dusun Ngebrak. Langkah- langkah dalam pendampingan adalah:
1). Membuat rancangan materi Tari Kuda Lumping yang digunakan sebagai bahan pelatihan berdasarkan hasil observasi.

2). Pelatihan Tari Kuda Lumping untuk meningkatkan garap kesenian tradisional dan kualitasnya, tidak meninggalkan sifat kerakyatannya. Dalampelatihan diharapkan untuk meningkatkan keterampilan (skill) penari, yaitu para penari lebih paham secara mendetail sehingga benar benar menguasai kemampuannya dari titik kelemahan hingga cara mengatasinya.

3). Workshop perancangan atau desain handycraft terbuat dari bambu dengan memberikan contoh-contoh garap kreatif.

4). Pendampingan akan diupayakan pencitraan Desa Mergowati melalui karakteristik kesenian tradisional dan handycraft, sesuai dengan keinginan masyarakat melalui kajian yang mendalam terhadap latar belakang kehidupan sosial budaya pendukungnya.

5). Pelaksana Pengabdian Pada Masyarakat (PPM) akan membantu mensosialisasikan kepada generasi muda setempat mengenai nilai kearifan lokal dibalik kesederhanaan kesenian rakyat. Dengan tujuan agar para generasi muda setempat dapat bersikap lebih dinamis dan reseptif terhadap kesenian tradisional serta potensi bambu yang ada disekitar sebagai kerajinan tangan yang dapat meningkatkan ekonomi.

e. Pergelaran/pameran hasil

Hasil dari pendapingan melalui kerja kreatif dipentaskan dan dipamerkan pada puncak acara perayaan Hari Ulang Tahun (HUT) Kemerdekaan Republik Indonesia ke 73 pada tanggal 17 Agustus 2018 di Balai Desa Mergowati.

\section{Partisipasi Mitra Dalam Pelaksanaan Program}

Mitra yang dimaksud dalam pelaksanaan program yaitu perangkat desa dan masyarakat Desa Mergowati. Mengingat peserta pelatihan akan 
dilakukan bersama masyarakat Desa Mergowati maka harus terkoordinasi dengan baik, terutama yang berkaitan dengan perijinan, materi pelatihan baik untuk seni tari maupun workshop handycraft, jadwal, serta persiapan pentas. Koordinasi dilakukan dengan memberikan pemahaman rencana kegiatan Pengabdian Pada Masyarakat (PPM) Tematik kepada pejabat pemerintahan desa dan masyarakat yang terkait.

a). Perangkat desa, mengarahkan pelaksana Pengabdian Pada Masyarakat (PPM) Tematik dan kelompok kesenian Kuda Lumping Kridho Turonggo, tentang pengembangan kreativitas seni tradisional kerakyatan agar lebih bervariasi mengikuti perubahan selera masyarakat.

b). Koordinator, yang ditunjuk oleh ketua kelompok kesenian Krido Turonggo, mengkoordinir pelatihan Tari Kuda Lumping.

c). Ketua karang taruna mengkoordinir workshop handycraft. Menyiapkan bahan, mengatur tempat dan jadual workshop.

d). Menyusun jadual dan persiapan pentas seni dan pameran, melibatkan seluruh warga binaan Pengabdian Pada Masyarakat (PPM) Tematik dan masyarakat setempat

\section{b. Target/luaran}

1. Hasil (output) yang ditargetkan dari kegiatan adalah;

a. Satu (1) karya inovasi Tari Kuda Lumping Kridho Turonggo

b. Tiga (3) karya handycraft terbuat dari bahan bambu dan gerabah.

c. Artikel Ilmiah yang dipublikasikan melalui Jurnal dengan judul "PeningkatanApresiasi Seni dan Budaya Masyarakat Desa Mergowati Kecamatan Sebagai Desa Wisata".

d. Hak Kekayakan Intelektual

\section{Kebaruan Program}

Peningkatan apresiasi seni dan budaya masyarakat dalam upaya mewujudkan Desa Mergowati Kecamatan Kedu sebagai Desa Wisata.
Mergowati akan mengembangkan potensi kesenian tradisional, individu (seniman), kelompok serta kekayaan lokal genius budaya masyarakat Desa Mergowati. Dengan demikian prosesnya akan secara menyeluruh meliputipemahaman konsep tari untuk wisatawan, kemampuan/skill sebagai penari, serta managemen atau tehnik pergelaran. Dengan demikian maka kreativitas dari peserta menjadi bagian yanag sangat penting, terutama dalam keberlanjutan program. Selain itu juga akan menanamkan dan mengaplikasikan nilai-nilai karakter melalui seni tari tradisional. Pengemasan seni tradisi kerakyatan sebagai event wisata, akan menjadi daya tarik yang luar biasa.

\section{PEMBAHASAN}

Pelaksanaan program Pengabdian Pada Masyarakat (PPM) Tematik Institut Seni Indonesia (ISI) Surakarta di Desa Mergowati dilaksanakan selama 4 (empat) bulan, dimulai dari bulan JuliOktober 2018. Pengabdian Pada Masyarakat (PPM) Tematik di Desa Mergowati melibatkan 14 (empat belas) mahasiswa sebagai pelaksana dengan latar belakang meliputi: Seni Karawitan, Seni Tari, Etnomusikologi, Kriya Seni, Seni Rupa Murni, Desain Komunikasi Visual, Desain Interior, Televisi dan Film.

Hasil kegiatan Pengabdian Pada Masyarakat (PPM) . Tematik selama 4 (empat) bulan dapat dilaporkan sebagai berikut:

\section{Pelatihan Kesenian Tradisional. \\ a. Tari Kuda Lumping.}

Kuda lumping merupakan salah satu cabang kesenian yang sudah lama tumbuh dan berkembang diberbagai daerah kabupaten di Jawa Tengah, salah satunya Kabupaten Temanggung. Desa Mergowati Kecamatan Kedu memiliki kelompok kesenian tari Jaranan atau Kuda Lumping Kridha Turonggo yang sangat dibanggakan. Kelompok kesenian Kuda Lumping Kridha Turonngo dibawah pimpinan Yudi dan juga sebagai pelatih. Kesenian Kuda Lumping sering dipentaskan 
untuk penyambutan tamu, sebagai hiburan warga masyarakat yang mempunyai hajat, atau acara-acara keperluan desa.

Berdasarkan dari hasil dialog dengan kepala desa dan kelompok kesenian Kridho Turonggo, pelaksanaan Pengabdian Pada Masyarakat (PPM) kali ini diharapkan dapat membantu mengembangkan atau menggarap kembali tarian Kuda Lumping agar gerak-geraknya lebih bervariasi dan secara penampilan lebih menarik (wawancara Sugiyanto, 29 September 2018). Bertepatan dengan pelaksanaan Pengabdian Pada Masyarakat (PPM) ini, BAPEDA Kabupaten Temanggung meminta agara TariKuda Lumping bisa dipentaskan sebagai pembukaan hari Musium Nasional di pendopo Kabupaten Temanggung pada tanggal 24 Agustus 2018. Sementara kepala desa juga menghendaki Tari Kuda Lumping juga bisa dipentaskan dalam acara peresmian balai Desa Mergowati pada tanggal 29 September 2018.

Tari Kuda Lumping disajikan oleh 9 (sembilan) orang penari dan 6 (enam) orang pemain musik. Proses latihan dilaksanakan di Dusun Kapal, para pemuda sangat antusias dan penuh semangat dalam mengikuti latihan. Dengan metode sharing sugestion, tidak menggurui namun saling berbagi.

Proses pelatihan Tari Kuda Lumping tidak bisa dilakukan setiap hari oleh karena warga sibuk mengolah tembakau. Kebetulan bulan Juli-Agustus masyarakat Mergowati sedang panen raya tembakau, oleh karena itu pelatihan dilakukan diselasela para seniman mengolah tembakau yaitu pukul 20.00-24.00. Latihan rutin setiap malam dilakukan satu minggu sebelum pementasan yaitu dari tanggal 18-23 Agustus 2018. Proses latihan diawali dengan mengapresiasi Tari Kuda Lumping yang sudah ada, yaitu dengan menonton bareng Tari Kuda Lumping dari awal hingga selesai. Kemudian dilanjutkan dengan dialog untuk memberikan masukan bagian mana saja yang dapat dikembangkan, baik dari gerak, pola lantai atau formasi dan iringannya. Setelah ada kesepakatan maka segera di tindak lanjuti dengan kerja kreatif.
Meskipun waktunya relatif pendek namun hasil pelatihan ini tidak mengecewakan. Hal ini tercermin dari antusias penonton yang sangat tinggi dan aplause penonton yang berulang-ulang. Hal ini juga terungkap dari pernyataan kepala desa yang menyampaikan bahwa pementasan tari Kuda Lumping terasa semakin dinamis (Wawancara, 29 September 2018).

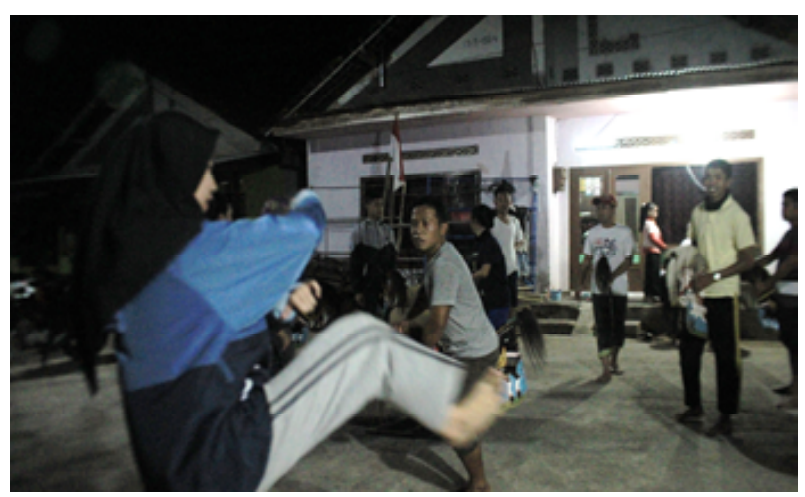

Gambar 1: Proses Pelatihan Kuda Lumping di Dusun Kapal (Dok. Tim PPM).

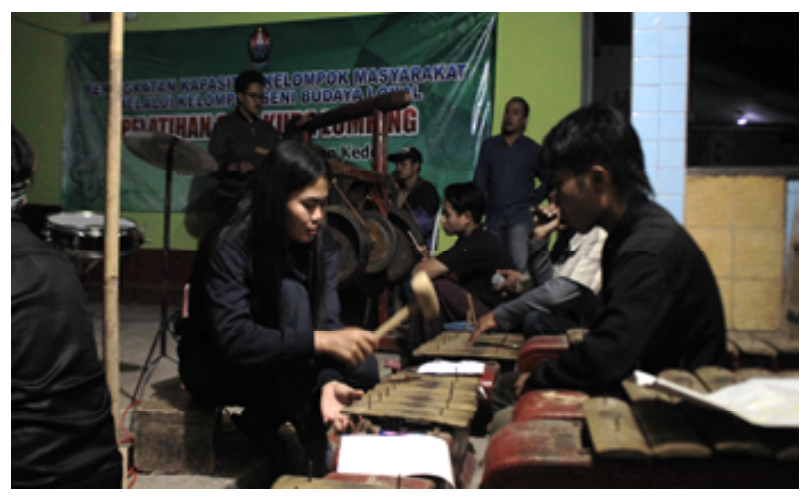

Gambar 2: Pelatihan Karawaitan Kuda Lumping di Dusun Kapal (Dok tim PPM) 


\section{Abdi Seni Jurnal Pengabdian Kepada Masyarakat}

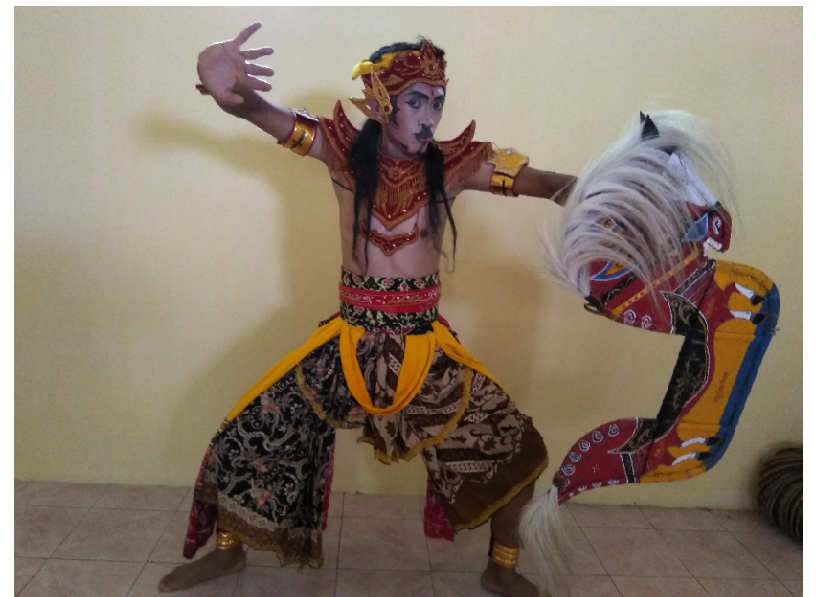

Gambar 3: Penari Kuda Lumping dengan busana lengkap berikut property

(Dok. Soemaryatmi).

\section{b. Pelatihan Tari Kreasi Baru}

1). Materi: Tari Kupu-Kupu

Pemilihan tari kreasi baru sebagai materi Pengabdian Pada Masyarakat (PPM) Tematik ini diharapkan selain dapat sebagai repertoar ekstrakurikuler kelas V (lima) dan VI (enam) Sekolah Dasar (SD) Negeri 1 Mergowati, dilakukan setiap hari, Selasa, Kamis, dan Jum'at, jam 11.00-12.30 WIB, diikuti oleh 20 (dua puluh) siswa. Akan tetapi juga tidak bisa sebagai materi pertunjukan, ketika Desa Mergowati sebagai desa wisata. Selain itu dapat dijadikan acuan materi dalam mengikuti ajang perlombaan seperti FLS2N.

Tari Kupu-Kupu adalah sebuah tarian yang menggambarkan tentang kupu-kupu yang mempunyai keaneka ragaman warna, yang sedang terbang kesana kemari serta hinggap dari satu bunga ke bunga yang lain, yang mengandung makna tentang keindahan serta kedamaian di bumi. Tarian KupuKupu didominasi oleh semua gerak tubuh, utamanya yaitu gerakan kaki dan tangan yang terus mengikuti ketukan irama kendang. Di samping itu, gerakan yang paling menonjol yaitu dikala para penarinya memainkan tangannya naik turun seraya memegang selendang berwarna cerah yang tampak mirip sayap kupu-kupu yang tengah terkembang.

\section{2). Materi: Tari Rigen}

Tari Rigen merupakan salah satu tari kreasi baru yang ditarikan secara kelompok. Tari Rigen merupakan materi pelatihan kelas V (lima) dan VI (enam) Sekolah Dasar (SD) Negeri 2 Mergowati, dilaksanakan setiap hari Senin dan Kamis, jam 11.00-12.30 WIB, diikuti oleh 27 siswa. Tarian Rigen menceritan tentang kegiatan seorang petani tembakau yang berada di Dusun Margowati. Rigen juga merupakan tempat untuk wadah tembakau yang sudah dipetik. Tari Rigen juga memperkenalkan kekayaan Desa Mergowati sebagai penghasil Rigen

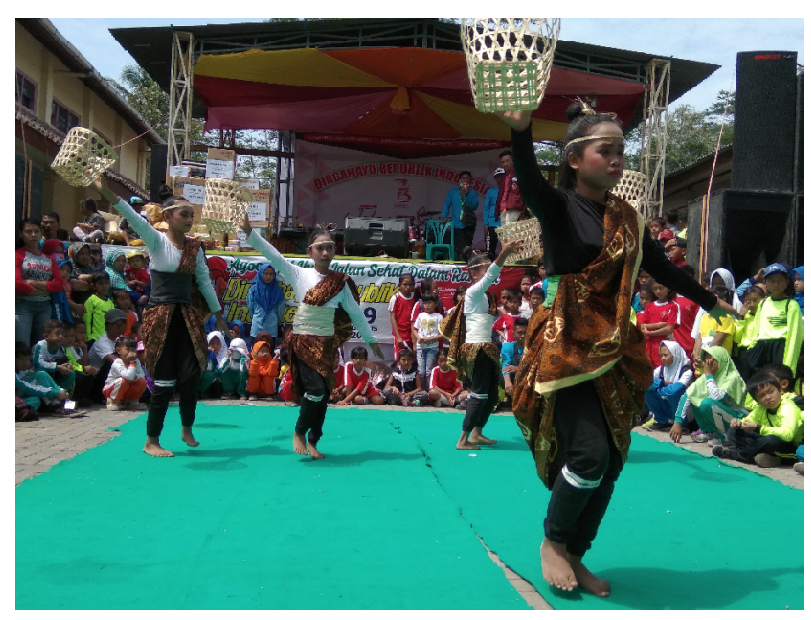

Gambar 5: Pementasan Tari Rigen di Balai Desa Mergowati

(Dok tim PPM).

\section{3). Materi : Tari Merak}

Tari Merak merupakan salah satu tari tradisional asal Jawa Barat yang menggambarkan ekspresi dan kehidupan burung merak. Tarian burung merak dibawakan oleh penari perempuan begitu anggun dan penuh pesona daya tarik. Tari Merak merupakan salah satu materi pelatihan kelas V (lima) dan VI (enam) Sekolah Dasar (SD) Negeri 2 Mergowati, dilaksanakan setiap hari Senin dan Kamis, jam 11.00-12.00 WIB, diikuti oleh 27 (dua puluh tujuh) siswa.

Gerak utama yang menjadi ruh dari tari Merak adalah gerakan burung merak jantan yang mengembangkan ekor indahnya untuk memikat 
merak betina. Kostum yang digunakan menggambarkan bentuk dan warna bulu-bulu merak seperti warna hijau, biru dan hitam. Ditambah dengan sepasang sayapnya yang melukiskan sayap atau ekor merak yang sedang dikembangkan. Para penari juga menggunakan mahkota yang makin menambah motif burung merak.

\section{c. Tembang Macapatan, dan Tembang Dolanan.}

Pengenalan titilaras tembang macapat dan dolanan. Materi yang disampaikan yaitu pengetahuan dasar tentang gamelan dan titilarasnya, teori singkat tembang dan praktik tembang macapat.

Pada tembang Macapat dan Dolanan diberi materi Pucung dan Gundul-gundul Pacul. Materi diberikan kepada siswa SD Negeri 1 Mergowati kelas V (lima) dan VI(enam), dengan pertimbangan tidak adanya alat gamelan sebagai media ajar menggunakan teknik vokal titilaras 1, 2, 3, 4, 5, 6, 7 ( ji, ro, lu, pat ma, nem, pi) untuk materi pembelajaran tembang macapat dan dolanan. Kemudian dalam pembelajaran difokuskan pada 2 (dua) jenis tembang macapat dan tembang Dolanan.

1) Syair tembang Macapat Pucung

a) Bapak Pucung, dudu watu dudu gunung Sabamu ing sendang,

Penclokamu lambung kering

Prateng wisma si pucung, wutah guwaya

b) Thole kuncung, lamun sira ngudi ngelmu Aja pisan sembrana

Awit iku migunani

Tanpa iku uripmu bakal rekasa

2) Syair tembang Dolanan Gundul-gundul Pacul Gundul-gundul pacul cul

Gemblelengan

Ngunggi-nyunggi wakulkul

Gemblelengan

Wakul glempang segane dadhi sak latar

Wakul glempang segane dadhi sak latar

\section{Workshop}

a. Kegiatan: Pemanfaatan bambu sebagai cup lampu dan vandel

Progam kerja pemanfaatan bambu dilakukan di Dusun Ngebrak, sebagai sasarannya adalah pemuda Karang Taruna Desa Ngebrak. Workshop dilaksanakan di rumah Sdr. Aswin (Ketua Karang Taruna), tanggal 1-25 Agustus 2018, pukul. 20.00 sd 24.00 WIB, dengan jumlah peserta 20 orang. Kegiatan diawali dengan menjelaskan tentang bambu, manfaat dan kerja kreatif mulai dari mendesain sampai proses akhir prototype lampu hias dengan cara dilukis cat pigmen, dan bentuk krawingan/luban. Untuk finishing, dihaluskan pada permukaan bambu menggunakan amplas.

\section{b. Branding Kopi Gunung Boto Desa Mergowati}

Sejak tahun 2012 Saud, pemilik Rumah Kopi Waloeh memulai usahanya dengan brand kopi pertamanya yaitu Kopi Waloeh. Beliau mengangkat brand waloeh karena terinspirasi dari cerita sekitar yaitu daerah Kedu.

Seiring berjalannya usaha beliau ingin mengembangkan brand kopinya menjadi ciri khas desanya sendiri yaitu Desa Mergowati. Desa Mergowati mempunyai peninggalan situs yang banyak, salah satunya berada di Gunung Boto. Oleh karena kebun kopi yang dimiliki juga berada di Gunung Boto maka beliau berinisiatif untuk membuat brand yang terinspirasi dari sejarah Gunung Boto sendiri. Kopi yang diproses memiliki 2 macam varian yaitu Arabica dan Robusta. Namun menurut pemilik Kopi Robusta adalah image dari Kabupaten Temanggung maka dari itu beliau memilih Robusta yang akan menjadi olahan kopi pada brand Gunung Boto. Selain memiliki 2 varian juga ada 2 karakter yaitu speciality dan premium, speciality untuk brand Kopi Waloeh dan premium untuk brand terbaru yang belum di sebar luaskan yaitu Kopi Gunung Boto.

Pembuatan logo \& kemasan Kopi Gunung Boto dirancang dengan ciri khas simple tapi elegan karena karakternya yaitu premium. Mengangkat cerita dari pemilik kopi menjelaskan bahwa kopi 


\section{Abdi Seni Jurnal Pengabdian Kepada Masyarakat}

yang dimiliki beliau proses pembuatannya selalu menggunakan petik merah. Artinya setiap biji kopi yang beliau panen hanya memproses bijikopi yang sudah matang dan berwarna cenderung merah. Hasil produksi kopi akan disebar luaskan atau dipasarkan pada bulan Oktober, dikemas dalam bentuk kopi bubuk. Logo yang digunakan pada packaging Kopi Waloeh secara tidak langsung sudah mempromosikan Desa Mergowati melalui tulisan Gunung Boto yang nota bene adalah bagian dari wilayah Desa Mergowati.

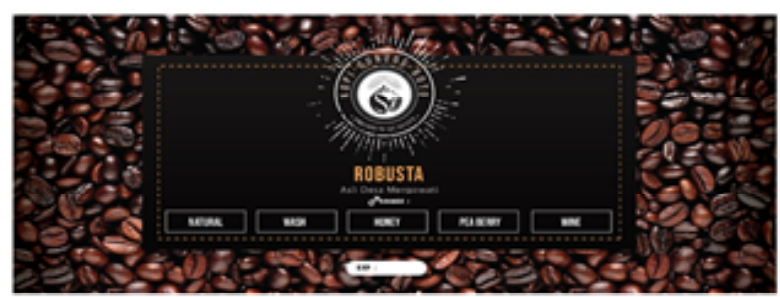

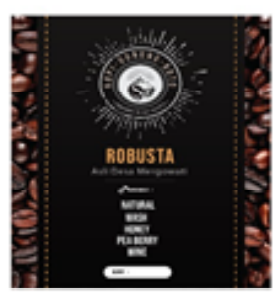
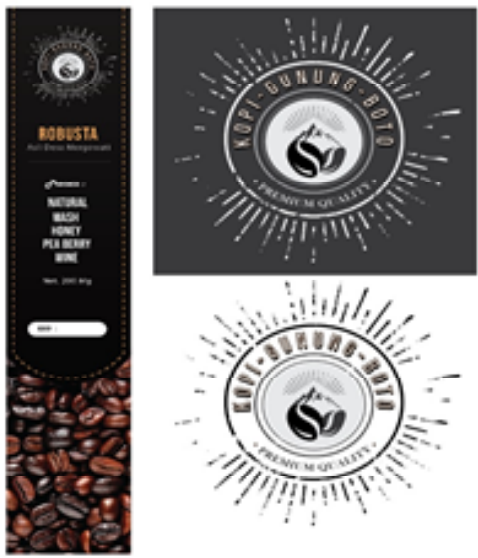

Gambar 6: Desain Logo Kopi Gunung Boto

c. Pembuatan ornamen pada gerabah pot

Ornamen adalah pola hias yang dibuat dengan digambar, dipahat, dan dicetak, untuk mendukung meningkatnya kualitas dan nilai pada suatu benda atau karya seni. Ornamen juga merupakan perihal yang akan menyertai bidang gambar (lukisan atau jenis karya lainnya) sebagai bagian dari struktur yang ada di dalam. Ornamen yang tidak hanya dapat dimanfaatkan untuk menghias suatu benda/produk fungsional tapi juga sebagai elemen penting dalam karya seni (lukisan, patung, grafis), sedangkan teknik visualisasinya tidak hanya digambar seperti yang dikenal selama ini, tapi bisa juga dipahat atau dicetak. Materi Workshop pada kesempatan kali untuk SMP 03 Kedu, Kelas VIII B, dan VIII C yang diikuti 25 siswa, dilaksanakan Setiap hari Rabu dan Kamis, jam $07.00-14.00$ WIB. Melukis ornamen geometri, tradisi, dan teknik warna sungging dengan pigmen pada pot bunga. Alat dan Bahan diperlukan meliputi: Pot Bunga dari gerabah, cat warna, pensil, kuas, penghapus, bensin, koran, spidol, gelas plastik, drawing pen.

\section{d. Melukis Ornamen Pada Gantungan Kunci}

Materi workshop yang diberikan yaitu melukis gantungan kunci dengan memanfaatkan limbah kayu dan teknik melukis untuk menghasilkan benda yang bermanfaat untuk kehidupan sehari-hari.

Dalam materimelukis gantungan kunci siswa diajak berkreasi membuat gantungan kunci yang diberi nama dan cita-cita para siswa sendiri. Dalam pelaksanaan pelatihan lukis gantungan kunci bermanfaat untuk peningkatan kreatifitas pengolahan barang bekas atau limbah kayu yang terdapat lingkungan di sekitarnya.

\section{Pengecatan Mural dan Menghias Caping}

a. Mural Di Gedung Balai Desa Mergowati

Mural adalah melukis di atas media dinding tembok atau permukaan luas yang bersifat permanen, dengan tujuan untuk memperindah suasana lingkungan sekitar. Sebagai pijakan dalam melukis mural di Balai Desa Mergowati, pertama dilakukan observasi dan wawancara dengan Bapak Lurah mengenai tempat, alat bahan, dan tema mural. Tema yang diangkat untuk lukis mural yaitu gambar kuda berkepala manusia dan tulisan "Sasono Margo Turonggo" sebagai identitas Gedung Balai Desa Mergowati.

Menurut sejarah Desa Mergowati dulu terkenal kudanya yaitu Kuda Sembrani. Apabila diikut sertakan dalam lomba pacuan kuda juga sering menjadi pemenang. Konon sejarahnya Dusun Kapal salah satu dusun yang terdapat di Desa Mergowati, adalah tempat memelihara dan melatih kuda-kuda perang pada jaman kerajaan Mataram 
Islam, jaman Raja Panembahan Senopati. Kata Kapal berasal dari kata kepel, yang artinya anak kuda (wawancara, Sugiyanto 17 Juni 2018). Berdasarkan sejarah yang ada tema mural yang diterapkan pada balai desa adalah gambar kuda berkepala manusia, dan bertuliskan "SASONO MARGO TURONGGO". Alat dan bahan: cat tembok, kuas, tangga/andang, projector, laptop, cup gelas, kertas manila

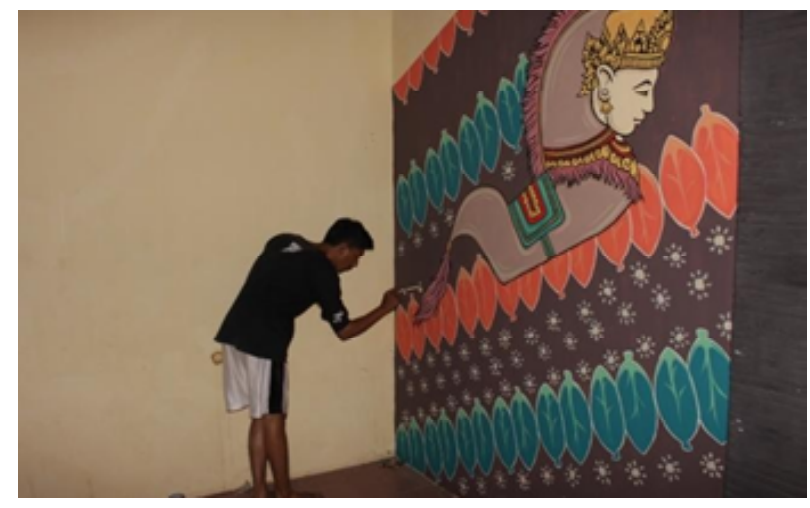

Gambar 7. Proses Pembuatan Mural Gedung Balai Desa Mergowati

(Dok. Tim PPM)

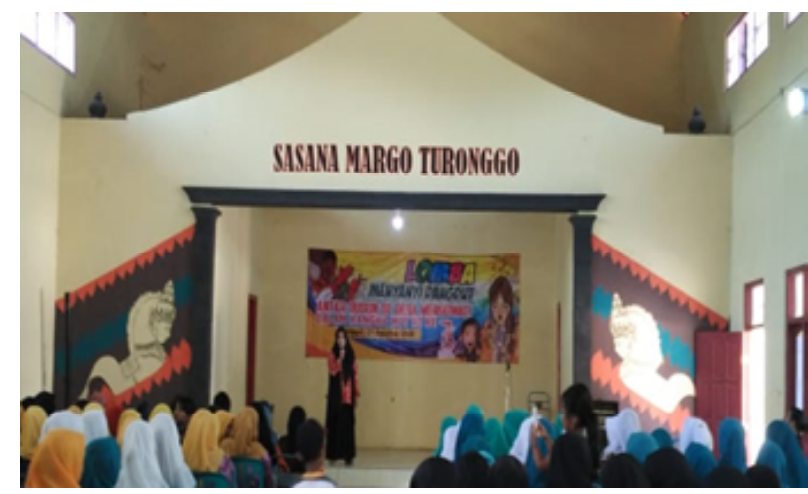

Gambar 8. Hasil Pembuatan Mural Gedung Balai

Desa Mergowati

(Dok. Tim PPM)

\section{b. Menghias Caping Gunung Boto}

Caping hias, adalah caping yang dihiasi dengan pernak pernik, sehingga nampak berbeda dan unik dibanding sebelumnya. Teknik lukis pada caping menggunakan tehnik stensil dengan cat semprot. Teknik ini sangat mudah digunakan untuk karakter lukis ekspresif yang memerlukan waktu yang sangat singkat. Menghias caping adalah permintaan ibu lurah, untuk keperluan dalam rangka persiapan Festival Gunung Boto pada tanggal 7 dan 8 Oktober 2018. Alat dan bahan yang akan di gunakan yaitu caping, cat tembok, cat semprot kuas, dan cup gelas

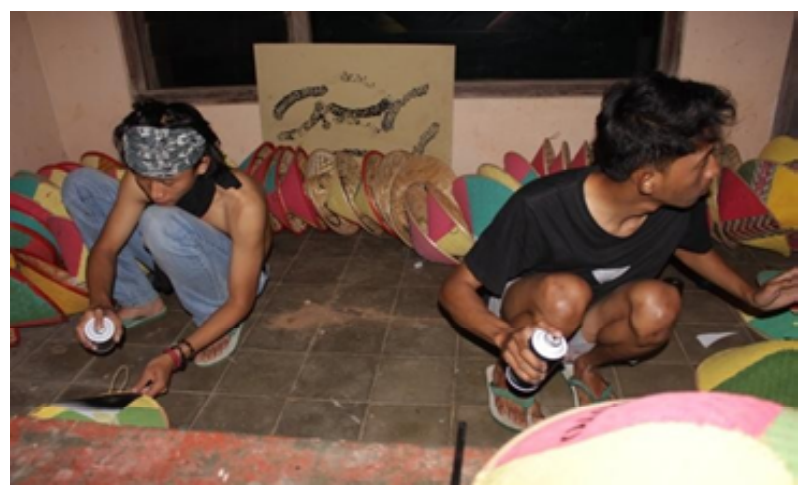

Gambar 9. Proses Menghias Caping (Dok. Tim PPM)

\section{Melestarikan Budaya Lokal Grebeg Gunung Boto}

Tradisi Grebeg Makukuan Gunung Boto merupakan salah satu upacara adat yang diselenggarakan setiap tanggal 27 Suro (menurut penanggalan Jawa). Upacara adat berlangsung di Dusun Gunung Boto, Desa Mergowati Kecamatan Kedu, Kabupaten Temanggung. Masyarakat mempercayai akan mendapatkan rezeki melimpah, dagangan laris, tanaman pertanian subur, dan warga yang menjadi pegawai dapat bekerja secara baik setelah mengikuti ritual upacara. Seperti yang disampaikan oleh Sugiyanto bahwa tradisi Grebeg Makukuan Gunung Boto ini juga merupakan,

a. Wujud rasa syukur warga masyarakat atas apa yang telah diterima selama ini,

b. Mohon keselamatan dan perlindungan agar perekonomian masyarakat Desa Margowati lebih berkembang.

c. Sebagai wadah menggalang persatuan dan kesatuan bagiseluruh umat beragama,

d. Melestarikan adat kebudayaan tradisional peninggalan nenek moyang masyarakat Desa Mergowati (wawancara, Sugiyanto, 7 September 2018) 
Mencermati pelaksanaan upacara adat Grebeg Gunung Boto tercermin bahwa kegiatan ini adalah kegiatan sosial yang tercermin dari dalam bentuk komunal (kebersamaan), religio magis (kepercayaan), dan tradisional. Tradisi grebeg yang dilakukan warga masyarakat Desa Mergowati dilaksanakan di Gunung Boto bukan tidak ada alasan, kegiatan dilaksanakan di Gunung Boto terdapat gentong yang besar, tidak di isi air tetapi dari dalamnya keluar air. Banyak sekali peziarah yang mengambil untuk dibawa pulang namun air dari dalam gentong, terus tidak pernah habis. (wawancara, Dewi, 7 September 2018) Secara tidak langsung ritual grebeg ini dimaksudkan sebagai usaha untuk memelihara sumber mata air agar tidak liar menjadi bajir atau malah mati menjadi kering dan harapannya kedepan tidak terjadi bencana.

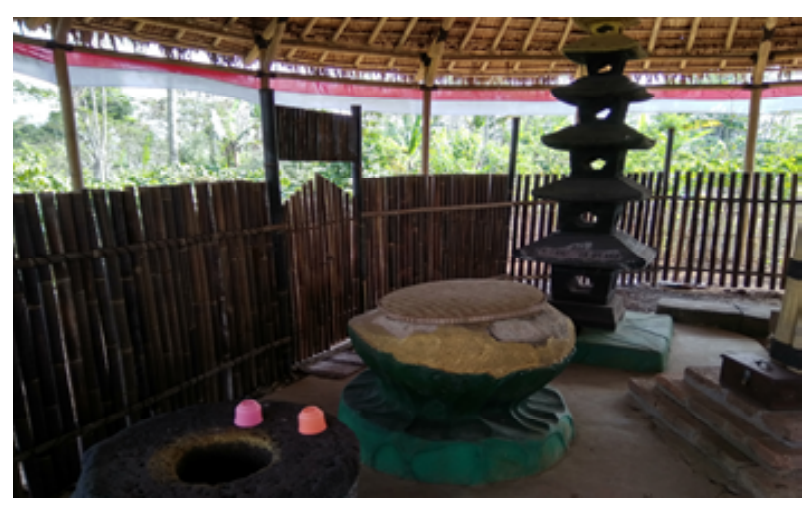

Gambar 10. Gentong Batu di Gunung Boto (Dok. Tim PPM)

Pelaksanaan Grebeg Gunung Boto diawali dengan prosesi arak-arakan gunungan yang berisi hasil bumi masyarakat setempat. Warga masyarakat masing-masing dusun membawa satu gunungan oleh karena Desa Mergowati teridiri dari 11 (sebelas) dusun, maka dalam arak-arakan ini terdapat 11 (sebelas) gunungan yang diarak dari balai desa menuju Gunung Boto.

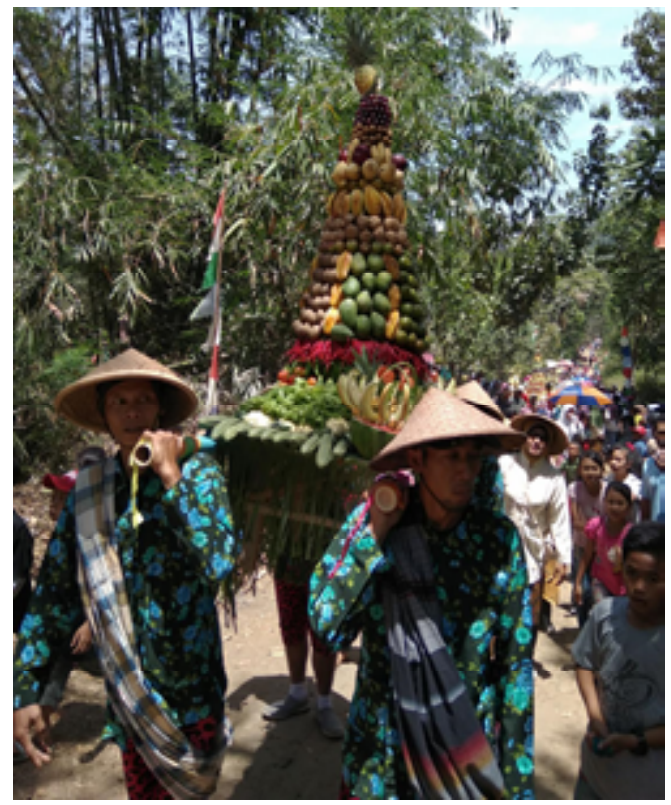

Gambar 11.Arak-Arakan Gunungan Menuju Gunung Boto

(Dok. Tim PPM)

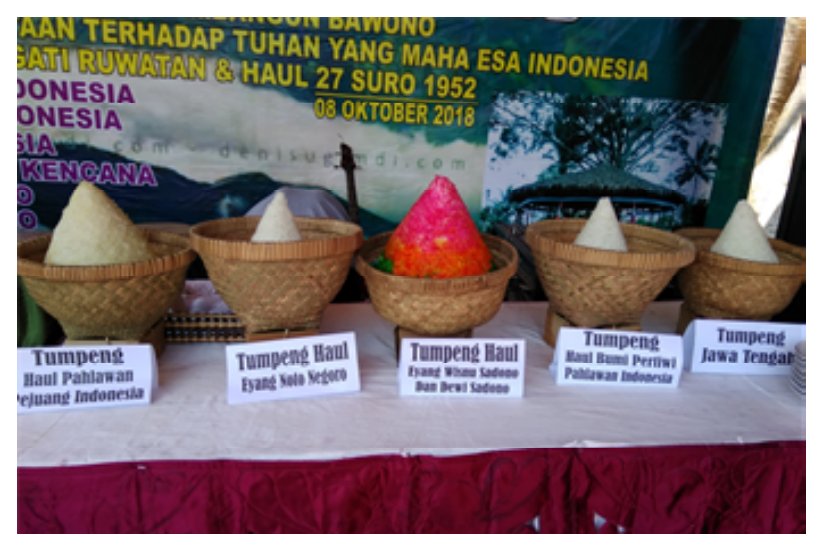

Gambar 12. Tumpeng Haul Dalam Grebeg Gunung Boto

(Dok. Tim PPM)

Pelaksanaan Grebeg Gunung Boto berjalan dengan lancar, dilihat antusias penonton yang cukup tinggi dalam mengikuti prosesi serta keterlibatan warga dalam pelaksanaannya, menunjukan bahwa kepala desa dan masyarakat sangat serius untuk menjadikan Desa Mergowati sebagai desa wisata. Hasil pengamatan di lapangan, para penonton banyak yang datang dari luar kota seperti Magelang, Yogya, Pesisir pantai Utara Jawa Tengah, Pekalongan dan juga sebagian dari Jawa Timur. 
Grebeg Gunung Boto merupakan salah satu agenda budaya yang berpotensi sebagai obyek kunjungan wisatawan ke Desa Mergowati. Warga masyarakat berkumpul di Gunung Boto, tak perduli lelaki perumpuan, tua ataupun muda, semua mengikuti prosesi dengan seksama. Kegiatan Grebeg Gunung Boto selain untuk mengharap berkah tentu juga untuk kerukunan antar warga.

Keterlibatan pelaksana Pengabdian Pada Masyarakat (PPM) adalah membantu menyusun schedule pelaksanaan Grebeg Gunung Boto, dan membantu mengatur prosesi arak-arakan gunungan.

\section{KESIMPULAN}

Pengabdian Pada Masyarakat (PPM) Tematik dengan judul Peningkatan Apresiasi Seni dan Budaya Masyarakat Dalam Upaya Mewujudkan Desa Mergowati Sebagai Desa Wisata, merupakan kegiatan dalam rangka meningkatkan kesadaran masyarakat Desa Mergowati terhadap potensi layak jual yang dimiliki dan mengajak masyarakat Mergowati memaksimalkan potensi, untuk dijadikan industri wisata demi peningkatan kesejahteraan sosial. Desa Mergowati adalah suatu wilayah pedesaan yang memiliki potensi keunikan dan daya tarik wisata yang khas yaitu, Lingkungan alam pedesaan yang sejuk asri, dan pemandangan yang indah karena daerah ini dikelilingi oleh gunung, kehidupan sosial masyarakat yang ramah dan penuh kekeluargaan, desa yang memiliki sejarah yang sangat menarik, didukung dengan situs-situs peninggalan kerajaan Mataram, dan memiliki seni budaya serta kerajinan tangan yang khas terbuat dari bambu.

Pengabdian Pada Masyarakat (PPM) Tematik di Desa Mergowati difokuskan pada peningkatkan apresiasi seni tradisional, workshop pemanfaatan bambu untuk suvenir dan peristiwa budaya (Grebeg Gunung Boto) bagi masyarakat Desa Mergowati.

Melalui kegiatan pelatihan seni tradisional Tari Kuda Lumping, Tari Kreasi Baru (Tari Rigen, Tari Kupu-Kupu, Tari Merak), tembang Mocopat, tembang dolanan, selain menambah wawasan atau kekayaan repertoar seni tradisional, peningkatan kemampuan ketrampilan/skill, juga telah meningkatkan kesadaran masyarakat, bahwa kesenian yang ada merupakan kekayaan yang memiliki potensi sebagai seni pertunjukan wisata. Kesadaran akan kecintaan terhadap kesenian yang dimiliki tercermin ketika Tari Kuda Lumping diminta oleh BAPEDA untuk dipentaskan pada pembukaan Hari Musium Nasional di Kabupaten Temanggung pada tanggal 23 Agustus 2018. Kepala desa, perangkat desa, penari, pengrawit dan seluruh pendukung kesenian merasa bangga dan percaya diri karena telah mendapatkan kepercayaan dari pemerintah Kabupaten Temanggung.

Workshop pemanfaatan bambu bertujuan untuk meningkatkan kreativitas masyarakat pengrajin anyaman bambu agar lebih produktif. Bambu yang selama ini diproduksi untuk alat-alat rumah tangga seperti gapyak, rigen, keranjang, dan centong, melalui workshop berhasil mengembangkan bambu sebagai handycraft untuk suvenir. Hasil dari workshop yang dilakukan adalah, beberapa bentuk cup lampu yang di berihiasan bentuk krawingan/ lubang yang menarik, pot bunga dari gerabah yang di beri ornamen dan di cat dengan warna-warna yang menarik, serta gantungan kunci dari limbah bambu yang dibuat dengan bermacam-macam bentuk dan di beri warna-warna yang menarik. Dari hasil workshop pemanfaatan bambu diharapkan muncul kegiatan yang bernuansa ekonomi kreatif.

Upacara-upacara adat atau tradisi ritual yang di laksanakan oleh masyarakat Desa Mergowati seperti Grebeg Gunung Boto sangat potensial untuk dijadikan sebagai aset wisata. Camat Kedu Agus Sri Sudaryanto menjelaskan "Grebeg Gunung Boto merupakan aset yang layak dikembangkan menjadi objek wisata religi. Desa Mergowati memiliki situs peninggalan Jaman Mataram yang masih perlu diteliti, dan dikembangkan sebagai wisata edukasi. "Oleh karena itu dengan mengapresiasi grebeg Gunung Boto diharapkan Desa Mergowati dapat dijadikan sebagai desa wisata unggulan," tandasnya 
(Sambutan dalam upacara Grebeg Gunung Boto, 8 Oktober 2018). Suciati salah seorang seorang dari Pekan Baru menuturkan dirinya bersama keluarga menyempatkan diri untuk menyaksikan Grebeg Gunung Boto sambil berwisata. Ia merasa terkesan dengan penyelenggaraan grebeg Makukuhan. Diharapkan acara tersebut bisa dikembangkan di masa-masa mendatang sebagai wahana untuk melestarikan budaya warisan nenek moyang yang adiluhung bernuansa religi(Wawancara, 8 Oktober 2018) .

Desa wisata adalah suatu bentuk integrasi antara atraksi, akomodasi dan fasilitas pendukung yang disajikan dalam suatu struktur kehidupan masyarakat yang menyatu dengan tata cara dan tradisi yang berlaku. Dengan pelaksanaan Pengabdian Pada Masyarakat (PPM) Tematik dengan judul Peningkatan Apresiasi Seni dan Budaya Masyarakat Dalam Upaya Mewujudkan Desa Mergowati Sebagai Desa Wisata, kegiatan ini dapat berimplikasi pada meningkatnya SDM Desa Mergowati, konservasi alam dan situs sejarah, serta pelestarian seni budaya secara berkelanjutan.

\section{DAFTAR PUSTAKA}

Alfian. 1986. Transformasi Sosial Budaya Dalam Pembangunan Nasional. Jakarta: UI Press.

Budhisantoso, 1994. "Kesenian dan Kebudayaan". Wiled: Jurnal Seni, Edisi I Juli, 1994, STSI. Surakarta,

Hadi Sumandiyo, 2006. Sosiologi Tari. Yogyakarta: ISI Press. , 2003 .Aspek Aspek Dasar Koreografi Kelompok. Yogyakarta: e'lkaphi. , 2005. Sosiologi Tari: Sebuah Pengenalan Awal. Yogyakarta: Pustaka.

Jazuli, M., 2012. Sosiologi Seni. Surakarta: UNS Press.

Murdowo, S. 2006. Objektivitas Imajinasi dalam Seni. Harmonia Journal of Arts Research and Education, 4(1), 22-31.

Nanik Sri Prihatini, 2008) 'Eksistensi Pertunjukan Kuda Kepang DiLereng Gunung Sumbing
Jawa Tengah Menuju Ke Sebuah Identitas". Artikel dalam Jurnal Greget Jurnal Ilmu dan Seni ISI Surakarta Vol.6. No. 1 Juli

Ratna, N. K., (2010). Metode Penelitian Kajian Budaya dan Ilmu Sosial Humaniora Pada Umumnya. Yogyakarta: Pustaka Pelajar.

Sal Murgiyanto, (2015). Pertunjukan Budaya dan Akal Sehat. Fakultas Seni Pertunjukan IKJ Kerjasama Komunitas SENRIPTA Yogyakarta.

Soedarsono, (1999). Seni Pertunjukan dan Pariwisata Rangkuman Esai tentang Seni Pertunjukan Indonesia dan Pariwisata. Yogyakarta: BP ISI.

Soemaryatmi, (2012. Dampak Akulturasi Budaya Pada Kesenian Rakyat Kecamatan Selo Boyolali dalam Panggung Jurnal Seni dan Budaya. Bandung: STSI. Vol 22. No. 1. Januari-Maret.

(2010). Pertunjukan Tari Campur Bawur Tradisi Syawalan Desa Lencoh Sela Boyolali dalam Harmonia Jurnal Pengetahuan dan Pemikiran Seni. Semarang: UNNES Vol. X. No. 1 Juni. , (2015). Sosiologi Seni Pertunjukan Pedesaan. Surakarta: ISI Press

Sugiyanto, 2018. "Sekilas Cerita Desa Mergowati”. Buku Panduan Grebeg Gunung Boto 2018.

\section{DAFTAR NARASUMBER}

1. Aswin 35 tahun. Ketua Karang Taruna Dusun Ngebrak.

2. Dewi Wahyu Sriningsih, 60 tahun. Pelindung Paguyuban Dewi Sri Sundoro Kedu.

3. Saud 37 tahun. Pemilik Rumah Kopi Waloeh

4. Suciati 58 tahun. Pengunjung/penonton Grebeg Gunung Boto.

5. Sugiyanto, 60 tahun. Kepala Desa Mergowati.

6. Yudi 32 tahun. Ketua Kelompok dan pelatih Kesenian Krido Turonggo. 